\title{
Significance and Practice of Creative Drama Education-Take Preschool Children Literature Teaching as an Example
}

\author{
Xu Ping \\ Zaozhuang Institute \\ Zaozhuang Institute of Primary Education \\ No. 1 North Road, Zaozhuang City, Shandong Province \\ E-mail: xupingdg@163.com
}

\begin{abstract}
Creative drama education plays an important role in the physical and mental development and ability cultivation of pre-primary students, which is conducive to cultivating students' practical ability, team awareness and collaboration ability, developing creativity, promoting mental health and enhancing aesthetic ability .The exploration and practice of creative drama education activities in pre-school children's literature teaching can help students to gradually acquire various abilities and enhance students' abilities by means of material selection and design, exercises and scene arrangement, improvisation, evaluation and assessment. The basic qualifications of prospective preschool education workers lay a good foundation for the smooth conduct of preschool education and teaching activities in the future.
\end{abstract}

Keywords-Creative Drama Education; Significance and function; Preschool Children Literature Teaching; Exploration and practice

\section{INTRODUCTION}

Pre-school children's literature is an important professional pre-school education required courses. By systematically studying pre-school children's literature courses, students can master the basic knowledge of pre-school children's literature systematically, read and understand excellent pre-school children's literature works, and further improve their reading ability, performance ability, oral communication skills and preliminary literature Appreciation and creation of ability to develop their literary attainment of a certain number of preschool children and promote their personality and selfimprovement of all-round development of human nature, so as to better understand the children, love children, improve students as a prospective child education workers basic qualities for the future. They successfully laid the foundation for kindergarten education and teaching activities.

However, for a long time, pre-school children's literature teaching lays emphasis on theoretical guidance and lacks the necessary practical activities so as to make students misunderstand the learning of preschool children's literature without fully realizing the important role of pre-school children's literature in promoting themselves and young

About the author: Xu Ping, female, Zaozhuang, born in 1973, master of literature and associate professor. The research direction is children's literature ancient Chinese literature and ancient Chinese culture. Now she is a teacher of Zaozhuang College of Primary Education. children's development. They think the theory is boring, the content is simple and boring, the style is naive and ridiculous, so lacking in enthusiasm for learning and more perfunctory on the learning of this course. This result is that theories were not remembered, students did not practice, and skills were not grasped. One year of learning did not improve much and effect. In this way, it is bound to affect the students' vocational skills training and future employment options. The use of creative drama education in teaching will reverse the current unfavorable situation in teaching so that students are full of interest and enthusiasm and actively engage in learning activities so as to develop students' various skills and abilities of imagination, language ability, aesthetic ability, teamwork ability.

\section{The DEVElOPMENT AND CONNOTATION OF CREATIVE DRAMA EDUCATION}

Creative drama education originated in the United States. In 1930, American theater educator Winifred Wards published his book "Creative Dramatic", marking the establishment of creative drama in children's theater education. In 1977, AATE organized a formal definition of "creative theater": it was an improvisational, non-performance, process-centric form of theater in which participants, under the guidance of a facilitator imagine, act and reflect on the real or imaginary experience of mankind. In 1983, Davis further pointed out that creative drama is the "guide" in a virtual situation, to guide "participants" to use pretend game instincts to explore, experience, develop, express, through the interaction of drama, to communicate with each other ideas, concepts and feelings to work together to imagine and experience the experience of human life to establish a consensus and mutual cooperation relationship [1].

The idea of creative drama education quickly spread to Taiwan and Hong Kong. In particular, Taiwan scholar Lin Mei-jun has devoted years of theoretical research and practical exploration of creative drama education. She summarizes the meaning of creative theater: "Creative theater is an improvised spontaneous classroom activity. Its development focuses on the participants' process of rebuilding experience and the expression of their spontaneity in speaking. In a naturally open 
classroom atmosphere, a leader uses motivational techniques, storytelling or props to motivate participants and encourages participants through various theater activities such as physical rhythms, impromptu mimes, facial features and situational dialogues use pretend game instincts to visualize and express in your own body and voice. In the group interaction, each participant must face, explore and solve the story of the characters or their own problems and situations, from which to experience life, to understand the relationship between man and I, to build self-confidence, and thus become a free creation. The solution of the problem, the unification of experience and the participants in society. [2]"

Creative drama education is mainly directed at children's drama, and its implementation environment mainly focuses on kindergartens and primary schools. It focuses on the experience and growth of children during theatrical performance, focusing on the solution of drama conflicts. Under the guidance and guidance of teachers, the rules of the game are clear and the implementation forms are flexible and diversified so that children can enjoy and display freely in a free and easy environment, happy to express themselves. It has the characteristics of process, improvisation, diversity, comprehensiveness, situation, group, completeness, repeatability and performance. It plays an important role in the healthy development and ability cultivation of children's mind and body. By attention and promotion.

\section{The SignifiCANCE AND FUnCTION OF CREATIVE DRAMA EDUCATION TO THE DEVELOPMENT OF PRESCHOOL EDUCATION MAJORS}

However, creative drama education is not limited to children's development. It plays an important role in cultivating and promoting many kinds of abilities of today's pre-school students and future preschool teachers. Creative theater mainly aims to achieve the goal of education through image, role play and creation of drama situations. Both performers and audiences can make students better understand life and life through the characters, plots and conflicts in the play, perceive the goodness, evil beauty and ugliness of human nature, develop personality and express themselves. That is to say not to play creative drama education knowledge and performance skills for learning purposes, but to understand society, think about life, cultivating ability, enhance their own literacy training for students to pay attention to through the drama, is of great importance to develop participants communication, expression, emotion, imagination, creativity, team awareness of quality and understanding [3].

\section{A. Creative drama education is conducive to cultivating and enhancing students' practical abilities.}

In recent years, the training objectives of local colleges and universities have turned to training applied talents, and practical teaching has become an important teaching method. In the classroom teaching of creative drama education activities. According to varieties of situations created by teaching content, a number of topics and role play, students think, organize, express languages and various body posture, plot and conflict settings, interact between the role to carry out creative performances through the effective guidance and inspiration of teachers. Through these forms, not only to stimulate students' interests in learning and participation in the passion, the key is to gradually develop and enhance students' language skills, imagination, ability to create ability and other practical ability.

\section{B. Creative drama education helps to improve students' team awareness and collaboration ability.}

Students enter social work, more importantly not his personal knowledge and ability, but his social development, have a good sense of teamwork and collaboration, whether to get along with others, adapt to the community's ability. Creative theater activities are group activities that require the joint efforts of groups to succeed. Throughout the theater activities, a group of people should get along well with each other and cooperate with each other in a concerted manner. They should have a good sense of democracy and a modest sense of humility when putting forward their own suggestions and accepting the opinions of others. This will enable students to gradually grasp the way to get along with others, team awareness and collaboration capabilities gradually improve, lay the foundation for them to successfully go to work in the future.

\section{Creative drama education is conducive to the development of students' creativity.}

In the 21 st century, more attention should be paid to cultivating creative and innovative talents. The essence of creative drama education lies in creativity and innovation. In the activity, participants are required to have enough imagination and creativity to try their best to deduce the plot, construct the situation, stimulate performance skills and abilities, and through team exploration, communication, research, continuous innovation, self-expression, outstanding personality. Through many activities training, we can gradually make learners stir up new ideas, create new ideas, discover new cognition and cultivate new abilities. As a result, student creativity is greatly enhanced in creative theater activities full of imagination and innovation.

\section{Creative drama education helps to promote students' mental health}

The definition of human health by the UN World Health Organization is: "Health refers not only to whether a person has any disease or weakness, but refers to a person's physical, psychological and social integrity. Mainly include physical health, mental health, spiritual health, social health, mental health, moral health and so on. Among them, mental health is more and more emphasized in modern society. With the development of society, competition intensifies, the pressure of modern people is more and more huge. For example, college students should be young and middle-aged, but their mental health problems have become increasingly evident. Drama education can help students to vent bad emotions, correct and develop students' self-awareness. In creative drama activities, students continuously solve contradictions and conflicts, experience different emotions and emotions, understand humility and understanding, learn empathy, 
demonstrate self-confidence, positive self-concept and selfawareness are gradually established and healthy psychology develops, EQ can be improved.

\section{E. Creative drama education helps to improve students' aesthetic ability}

Drama is a kind of integrated art integrating literature, fine arts, music, dance, costumes and so on. It plays an important and direct role in cultivating students' aesthetic ability. Creative drama is a tangible, artistic and plurilateral art form. Through creative drama activities, students can not only experience the "form" of art, but also experience the "environment" of art. In a specific drama situation, they can use Intuitive, visual way to feel the beauty of the arts [3]. Moreover, in creative drama activities, students must devote themselves wholeheartedly, including affection, sensory, intellectual input, including their own and the environment, physical and psychological, individual and social, human reality and potential. It enables students to immerse themselves in, continue to feel, experience, comprehend, through the physical and mental cooperation to show, show, so that students recognize the charm of art in the event, being infected, resonate, so as to enhance the aesthetic ability of students.

\section{EXPLORATION AND PRACTICE OF CREATIVE DRAMA EDUCATION ACTIVITIES IN PRESCHOOL CHILDREN LITERATURE TEACHING}

Creative drama education is not a boring theory, but more emphasis is placed on practice and experience. Therefore, through the practice of teaching creative drama education activities, so that students in the specific performance activities to try and experience in order to truly comprehend the creative drama education connotation, so as to develop students' abilities.

\section{A. Material selection and design}

Creative drama education activities are flexible and open, including rhythm, mime, role playing, imitation, storytelling, drama, drama and other forms. Teachers according to different teaching content, students and students can discuss the form and content of performance, selection and design. Such as children's songs can be designed into rhythm and role-playing, fairy tales and children's stories and children's poetry, narrative poems, fairy poetry and toddler drama can be designed to say story, mime, drama, drama and so on. In addition to allow students to use different ways of expression and performance, try to play different characters, animal characters, imagination and innovation.

In each module of learning, you can select a few topics, to the students group design. Each group of about seven or eight individuals, respectively, to receive one or two topics to discuss, design the entire performance process, the role allocation. Students are encouraged to innovate, such as creating characters, dialogues, plots, scenes, and even changing the subject and ending. Such as children's song "dwarf duck", not only can be designed to perform rhythmic performances, but also can be designed into a drama. Teachers can pre-design a scene: duck mother ducklings go to the river to swim, what happens? Guide students to think about the imagination, and thus become a small theater performance.

\section{B. Excise and scene layout}

Students in accordance with the group for discussion and exercises, the discussion includes the role of arrangement, the layout of the scene, the lines of characters, the use of props, plot convergence and so on [4]. After a brief discussion of the end of a simple exercise, no more than 15 minutes. Teachers tour the guide, participate in student activities, understand each group's design ideas and make constructive comments. For example, Professor Tang Sulan's fairy tale "Stupid Wolf's Story," "Half-Hour Dad" can be designed into a dramatic performance. Students independently increase their roles and lines, design activities scenes, imagine the role of facial expressions and mental activities, so that the whole story in the performance of the process more lively and interesting. If some students stupid wolf go out to meet many neighbors, and they say hello; stupid wolf duckling foraging when encountered frog ridicule when he picked up a duckling unlike his, and so on, this expresses students' ability to innovation.

Students can temporarily arrange some scenes and props. Due to regular performances, you can prepare several sets in advance, such as forests, meadows, sea, castles, etc., if you need to use, can be taken out directly. Some props can also be prepared in advance to prepare for contingencies, such as trees, grass, animal headdresses, masks and so on.

\section{Improvised performance.}

The groups conducted improvised performances in turn, temporarily arranging some relevant scenes and props. Each participant activities according to their assigned tasks, such as protagonist supporting actor, performers, narrator, service personnel and so on. Encourage students to bold imagination and creativity in performance, improvised performance, full of explosiveness and passion. Such as performing children's play "Little Bear Tooth extraction", and some students to design two tooth insects, proud singing and dancing came to the Cubs, make the plot more lively and interesting. The "wonderful performance of middle school students" between rejuvenation and design a wonderful details: almost secretly wearing a white coat after her father left, in front of the mirror to turn, feel good, fully demonstrated the confidence and the kitten is conceit, seems to pose as doctors.

Creative drama education is a form of art that is full of context in which students not only have the most intuitive artistic experience, but also deeply feel the effects of theater activities. 


\section{Evaluation and assessment.}

Evaluation sessions are essential for creative drama education. Each performance is over, teachers should organize students to evaluate. These evaluations include not only the internal mutual assessment of the group, the mutual evaluation of each group, but also the teacher's evaluation and summary of each group. Evaluation contains a wide range of content, including the completion of the evaluation of the drama goal; evaluation of the organization of the event; evaluation of the performance link; evaluation of the ability to comprehend the work; assessment of speaking ability; assessment of body language expression, evaluation of innovative ability and many more [4].

In the evaluation of the merits and demerits, appropriate measures to improve the direction of efforts, so that students not only recognize their performance in the theater activities, but also clear their space for improvement. In addition, each activity and evaluation are also included in the assessment of the entire curriculum. This process of assessment, focusing on practical training and the cultivation of a variety of abilities, is an incentive and promotion for students. A complete set of scientific evaluation system for creative drama education in pre-school children's literature course is quite necessary.

In addition to classroom teaching, in order to strengthen and consolidate students' drama activities and enhance students' ability to perform, students can be organized to organize drama associations, perform drama shows and competitions, and help young children train creative drama education activities during their internship with kindergartens so as to enhance students' awareness of creative drama education to enhance their ability to create innovative.

\section{CONCLUSION}

Creative drama is a comprehensive art, hidden infinite imagination space, sincere emotional state, wonderful life ideal [5]. through the design and performance, feel the beauty of the beauty of the drama art, the beauty of the picture, the beauty of the plot, enrich the students' artistic knowledge and emotion, and subtly influence the overall development of the students. In short, creative drama education activities in preschool children's literature teaching, give full play to the role of creative drama, leading students to learn independently, consciously experience [6] self-expression. Through learning, exploring, acting and feedback, they mature gradually and lay a good foundation for their future work practices.

\section{REFERENCES}

[1] Feng Jun-zhu.Study on Teachers' Guidance Based on Creative Drama A Kindergarten in Harbin as an Example [J].Master's thesis. 2016.06.

[2] Lin Mei-jun. Creative drama theory and practice [M]. Shanghai. Fudan university press

[3] Suo Li-zhen. the preliminary exploration of creative drama education in higher vocational colleges [j]. Chinese staff education. 2014.08.

[4] Dong Shu-yan. the application of creative drama education in children's literature course [j]. Asia-Pacific education. 2015.07.

[5] Zhu Kai-li. the value of creative children's plays [j]. popular literature 2015. 20.

[6] Ma Ling. discussion on the reform of drama teaching in preschool education major [j].Asia-Pacific education. 2015.10 . 